\title{
Article \\ Urinary Volatiles and Chemical Characterisation for the Non-Invasive Detection of Prostate and Bladder Cancers
}

\author{
Heena Tyagi ${ }^{1}$, Emma Daulton ${ }^{1}$, Ayman S. Bannaga ${ }^{2,3}{ }^{(D}$, Ramesh P. Arasaradnam $2,3,4,5$ (D) \\ and James A. Covington 1,*(D) \\ 1 School of Engineering, University of Warwick, Coventry CV4 7AL, UK; Heena.Tyagi@warwick.ac.uk (H.T.); \\ e.daulton@warwick.ac.uk (E.D.) \\ 2 Department of Gastroenterology, University Hospital Coventry \& Warwickshire, Coventry CV2 2DX, UK; \\ ayman.bannaga@warwick.ac.uk (A.S.B.); r.arasaradnam@warwick.ac.uk (R.P.A.) \\ 3 Warwick Medical School, University of Warwick, Coventry CV4 7HL, UK \\ 4 School of Health Sciences, Coventry University, Coventry CV1 5FB, UK \\ 5 School of Biological Sciences, University of Leicester, Leicester LE1 7RH, UK \\ * Correspondence: j.a.covington@warwick.ac.uk
}

Citation: Tyagi, H.; Daulton, E.; Bannaga, A.S.; Arasaradnam, R.P.; Covington, J.A. Urinary Volatiles and Chemical Characterisation for the Non-Invasive Detection of Prostate and Bladder Cancers. Biosensors 2021, 11, 437. https://doi.org/10.3390/ bios11110437

Received: 30 September 2021

Accepted: 29 October 2021

Published: 3 November 2021

Publisher's Note: MDPI stays neutral with regard to jurisdictional claims in published maps and institutional affiliations.

Copyright: (c) 2021 by the authors. Licensee MDPI, Basel, Switzerland. This article is an open access article distributed under the terms and conditions of the Creative Commons Attribution (CC BY) license (https:/ / creativecommons.org/licenses/by/ $4.0 /)$.

\begin{abstract}
Bladder cancer (BCa) and prostate cancer (PCa) are some of the most common cancers in the world. In both $\mathrm{BCa}$ and $\mathrm{PCa}$, the diagnosis is often confirmed with an invasive technique that carries a risk to the patient. Consequently, a non-invasive diagnostic approach would be medically desirable and beneficial to the patient. The use of volatile organic compounds (VOCs) for disease diagnosis, including cancer, is a promising research area that could support the diagnosis process. In this study, we investigated the urinary VOC profiles in $\mathrm{BCa}$, PCa patients and non-cancerous controls by using gas chromatography-ion mobility spectrometry (GC-IMS) and gas chromatography time-of-flight mass spectrometry (GC-TOF-MS) to analyse patient samples. GC-IMS separated BCa from PCa (area under the curve: AUC: 0.97 (0.93-1.00)), BCa vs. non-cancerous (AUC: 0.95 (0.90-0.99)) and PCa vs. non-cancerous (AUC: 0.89 (0.83-0.94)) whereas GC-TOF-MS differentiated BCa from PCa (AUC: 0.84 (0.73-0.93)), BCa vs. non-cancerous (AUC: 0.81 (0.70-0.90)) and PCa vs. non-cancerous (AUC: 0.94 (0.90-0.97)). According to our study, a total of 34 biomarkers were found using GC-TOF-MS data, of which 13 VOCs were associated with $\mathrm{BCa}$, seven were associated with PCa, and 14 VOCs were found in the comparison of BCa and PCa.
\end{abstract}

Keywords: bladder cancer; prostate cancer; urinary biomarkers; urinary VOCs; machine olfaction; GC-IMS; GC-TOF-MS

\section{Introduction}

Early detection and diagnosis of cancer remains a key goal to improve the prognosis and life expectancy of patients [1-4]. Globally, cancer results in some of the highest mortality rates for any disease. In 2020 alone there were more than 19 million new cancer diagnoses and almost 10 million deaths [5]. The UK is a major contributor to this, with some of the highest cancer rates in the world. It is amongst the top $10 \%$ of countries, with the highest number of new cases of cancer [6]. These figures emphasize the importance of using screening methods to improve disease diagnosis and to reduce cancer morbidity [7].

Bladder cancer (BCa) is the ninth most common cancer worldwide and is also one of the most difficult cancers to diagnose and clinically manage [8,9]. Cystoscopy followed by transurethral resection of a bladder tumour (TURBT) with biopsy and histological assessments are considered to be the 'Gold Standard' for the diagnosis of BCa [10]. However, cystoscopy is invasive in nature, and can cause pain, urinary infections, and blood loss in some cases [11,12]. To aid in the diagnosis of $\mathrm{BCa}$, a range of urine tests have been developed including the bladder tumour antigen (BTA) test, nuclear matrix protein 22 (NMP22), urinary bladder cancer antigen (UBC), and fibrin degradation products (FDP). 
Unfortunately, none of these tests have demonstrated sufficient specificity or sensitivity as a screening test [13].

Prostate cancer (PCa) occurs in men and is the sixth most common cancer worldwide [14-16]. For prostate cancer, PSA (prostate-specific antigen) is a commonly used blood test. However, it lacks sensitivity and specificity. PSA can be used for monitoring PC progression in both symptomatic and asymptomatic patients [17]. The downsides of PSA, as a diagnostic test for PCa patients, are mainly related to the high false-positive rate. PSA can be raised in urinary and prostate infections or other conditions such as benign prostatic hyperplasia (BHP) [18]. Therefore, a raised PSA level can lead to unnecessary biopsies, which may end up causing fever, pain, bleeding, and infection to the patient [19-21]. Recent European Association of Urology guidelines advise undertaking a multiparametric magnetic resonance scan on all patients prior to confirmatory biopsies; however, this is not always accessible, especially in low-resource settings [22].

One area receiving significant interest is in the use of volatile organic compounds (VOCs) to diagnose and monitor cancer. VOCs are chemical compounds that are either produced in vitro or are introduced externally and can indicate the presence, or absence, of disease in the body. The concept first emerged after reports indicated that dogs could recognise cancer by sniffing biological samples [23]. Since this discovery, researchers have reported that VOCs could be used to detect a broad range of cancers including lung, colorectal and pancreatic cancer [24-27].

Urine is a common biological source of VOCs, as the components present are either the intermediate products or end products of metabolic activities occurring inside the human body [28]. A study published in 2016 provided significant evidence for the use of urinary VOCs for distinguishing $\mathrm{BCa}$, from a total of 72 urine samples the results showed an accuracy of $89 \%, 90 \%$ sensitivity, and $88 \%$ specificity using PLS-DA (partial least squares discriminant analysis) on GC-MS (gas chromatography-mass spectrometry) data [29].

Urine cytology is a non-invasive test which uses urine as biological modality for the presence of cancer. Several studies showed that though it exhibits high specificity, the sensitivity and specificity highly depend on collection method and cancer grade [30-32].

The gold standard for the analysis of VOCs remains GC-MS, but it is expensive, requiring specialised equipment and trained staff, making it difficult to implement in a point of care scenario. A variant of this is GC-TOF-MS (gas chromatography-time of flight-mass spectrometry), which is a similar technique used for multidimensional analysis of complex samples with the potential to identify an even greater number of VOCs [33,34]. However, more recently a range of other techniques have been reported that have the potential to be used at the point of care. GC-IMS (gas chromatography-ion mobility spectrometry) is one such technique, it provides high sensitivity and selectivity, and the GC-IMS can be created in a portable form factor and can use nitrogen or air as the carrier gas. However, it is less able to identify specific biomarkers and it is unable to identify chemicals with a low proton affinity. Our group has reported the use of this method with a range of different diseases [35,36]. Thus, the combination of GC-TOF-MS, which can provide a means of identifying specific biomarkers, with GC-IMS, a lower cost platform, using air as the carrier and thus facilitating ward use, is advantageous.

The study aimed to identify and test the potential of urinary biomarkers to distinguish between two different cancers and healthy controls using both GC-TOF-MS and GC-IMS. We believe this is the first time that GC-IMS has been used with these cancers in combination with GC-TOF-MS.

\section{Materials and Methods}

\subsection{Urine Samples}

A total of 106 patients were recruited after providing informed consent at University Hospital Coventry and Warwickshire NHS Trust, UK. Patients were recruited prior to anti-cancer treatment. This study was approved by Coventry and Warwickshire and North-East Yorkshire NHS Ethics Committees (Ref 18717 and Ref 260179). Urine samples 
were collected in standard universal sterile specimen containers and frozen within $2 \mathrm{~h}$ at $-80{ }^{\circ} \mathrm{C}$ for subsequent batch analysis and according to standard operating procedures, compliant with tissue bank requirements under Human Tissue Act 2004. No chemicals were added to the urine before freezing, as we have previously shown that urine samples remain stable for extended periods of time at this temperature [37]. Prior to analysis the samples were transferred to the University of Warwick and briefly stored at $-20^{\circ} \mathrm{C}$. The samples were defrosted in a laboratory fridge at $4{ }^{\circ} \mathrm{C}$ and aliquoted into $20 \mathrm{~mL}$ glass sample vials with a crimp cap. We used $5 \mathrm{~mL}$ of each urine sample for the analysis with GC-IMS and GC-TOF-MS. Of the 106 urine samples collected, 15 patients had confirmed $\mathrm{BCa}, 55$ were confirmed $\mathrm{PCa}$, and there were 36 non-cancerous controls. The mean age of the BCa patients was 70 years and the mean age of the PCa patients was 72 years. The demographic data of the subjects are illustrated in Table 1.

Table 1. Demographic data for subject groups.

\begin{tabular}{|c|c|c|c|}
\hline Group & Bladder Cancer & Prostate Cancer & Non-Cancerous \\
\hline Number of samples & 15 & 55 & 36 \\
\hline Mean Age (years) & 70.0 & 71.9 & 62.5 \\
\hline Sex: Male/Female & $12: 3$ & All Male & $24: 12$ \\
\hline Mean BMI $\left(\mathrm{Kg} / \mathrm{m}^{2}\right)$ & 24.4 & 27.5 & 30.9 \\
\hline $\begin{array}{l}\text { Current Smoker } \\
\mathrm{n}(\% \text { of patients })\end{array}$ & $1(6.7 \%)$ & $6(10.9 \%)$ & $3(8.3 \%)$ \\
\hline Mean PSA level (ng/mL) & - & $20.6(3.6-153.90)$ & - \\
\hline \multirow{36}{*}{ Gleason score } & \multirow{36}{*}{-} & Case $01 \quad 4+5=9$ & \\
\hline & & Case $02 \quad 3+4=7$ & \\
\hline & & Case $03 \quad 3+3=6$ & \\
\hline & & Case $04 \quad 4+5=9$ & \\
\hline & & Case $05 \quad 4+5=9$ & \\
\hline & & Case $06 \quad 3+4=7$ & \\
\hline & & Case $07 \quad 3+4=7$ & \\
\hline & & Case $08 \quad 3+5=8$ & \\
\hline & & Case $09 \quad 5+4=9$ & \\
\hline & & Case $10 \quad 3+4=7$ & \\
\hline & & Case $11 \quad 3+3=6$ & \\
\hline & & Case $12 \quad 3+4=7$ & \\
\hline & & Case $13 \quad 3+3=6$ & \\
\hline & & Case $14 \quad 4+5=9$ & \\
\hline & & Case $15 \quad 3+4=7$ & \\
\hline & & Case $16 \quad 3+4=7$ & \\
\hline & & Case $17 \quad 3+4=7$ & \\
\hline & & Case $18 \quad 3+4=7$ & \\
\hline & & Case $19 \quad 3+4=7$ & \\
\hline & & Case $20 \quad 3+3=6$ & \\
\hline & & Case $21 \quad 4+5=9$ & \\
\hline & & Case $22 \quad 3+3=6$ & \\
\hline & & Case $23 \quad 4+3=7$ & \\
\hline & & Case $24 \quad 3+4=7$ & \\
\hline & & Case $25 \quad 4+4=8$ & \\
\hline & & Case $26 \quad 3+3=6$ & \\
\hline & & Case $27 \quad 4+5=9$ & \\
\hline & & Case $28 \quad 4+4=8$ & \\
\hline & & Case $29 \quad 3+3=6$ & \\
\hline & & Case $30 \quad 3+3=6$ & \\
\hline & & Case $31 \quad 4+4=8$ & \\
\hline & & Case $32 \quad 3+4=7$ & \\
\hline & & Case $33 \quad 4+5=9$ & \\
\hline & & Case $34 \quad 3+4=7$ & \\
\hline & & Case $35 \quad 3+4=7$ & \\
\hline & & Case $36 \quad 3+4=7$ & \\
\hline
\end{tabular}


Table 1. Cont.

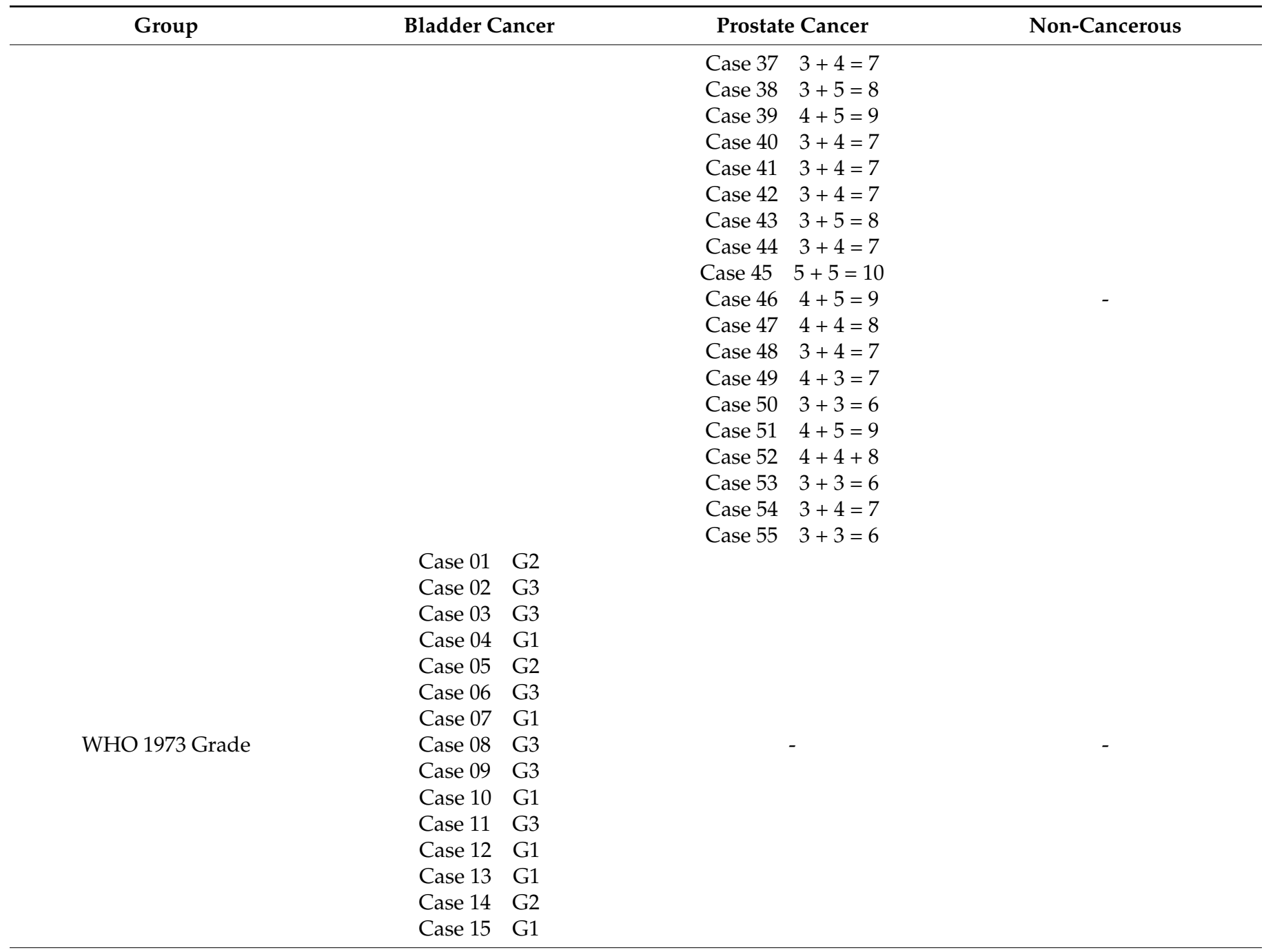

Prostate cancer Gleason grading:

Score $\leq 6$, pattern $\leq 3+3$. This refers to Grade 1 . Tumour cells look like normal prostate cells with only individual discrete well-formed glands.

Score 7, pattern $3+4$. This refers to Grade 2. Tumour with well-form glands and lesser component of poorly differentiated glands.

Score 7, pattern $4+3$. This refers to Grade 3. Tumour has predominantly poorly formed/fused/cribriform glands with lesser component of well-formed glands.

Score 8 , pattern $4+4,3+5$ and $5+3$. This refers to Grade 4 . Tumour with only poorly formed/fused/cribriform glands.

Score 9 or 10, pattern $4+5,5+4$ and $5+5$. This refers to Grade 5. Tumour lacking gland formation (or with necrosis) with or without poorly formed/fused/cribriform glands [38].

G1 low grade differentiation, G2 moderate grade differentiation and G3 is high grade differentiation [39].

\subsection{Analytical Devices}

\subsubsection{G.A.S. FlavourSpec Gas Chromatography-Ion Mobility Spectrometry (GC-IMS)}

The G.A.S FlavourSpec (Germany) uses a GC-IMS measurement technique to analyse VOCs. GC-IMS is a method used in various applications, such as detection of explosives and chemicals [40-42], air quality [43], health and disease detection [44-46] and food [47-49]. The method is formed of two stages. The first stage is a GC component that pre-separates chemicals based on their interaction with a retentive coating on the inside of a GC column. Thus, chemicals elude from the GC at different times [50]. These chemicals are further analysed using a drift-tube IMS method. Here, the chemicals are ionised (using a tritium source in our case) and pass along a drift-tube, propelled by a high electric field. Against the flow of ions, a buffer gas (using nitrogen in this case) is passed. The buffer gas and 
the ions collide resulting in a loss of momentum of the ions. Thus, the transit time along the tube is a function of the interaction of the ion with the electric field and the number of collisions with the buffer gas. This provides two-dimensional separation of the chemical components [48,51].

For analysis, glass vials containing samples were transferred to an autosampler fitted to the GC-IMS. The sample tray was chilled to $4{ }^{\circ} \mathrm{C}$ to reduce sample degradation during sample analysis. Each sample was heated to $40^{\circ} \mathrm{C}$ and agitated for 10 min before sampling. The autosampler then took $0.5 \mathrm{~mL}$ of sample headspace and directly injected it into the GC-IMS. Urinary headspace was defined as the volume of gas above the urine sample inside the vial, which was in chemical equilibrium with liquid phase urine. The machine settings for analysis were as follows: E1: $150 \mathrm{~mL} / \mathrm{min}$ (for the drift tube IMS), E2: $20 \mathrm{~mL} / \mathrm{min}$ (for the GC column), and the pump was set to $25 \%$. The total run time per sample was $10 \mathrm{~min}$. The temperatures were set to T1 (IMS): $45^{\circ} \mathrm{C}$, T2 (column): $80{ }^{\circ} \mathrm{C}$, and $\mathrm{T} 3$ (injector): $70^{\circ} \mathrm{C}$.

\subsubsection{Markes Gas Chromatography Time-of-Flight Mass Spectrometry (GC-TOF-MS)}

GC-TOF-MS operates by analysing the time of flight of ions and analyse them according to their mass-to-charge ratio. The GC-TOF-MS system used was a combination of a TRACE 1300 GC (Thermo Fisher Scientific, Loughborough, UK) and a BenchTOF-HD TOF-MS (Markes Intl., Llantrisant, UK). This system also included a high-throughput autosampler and a thermal desorption unit, ULTRA-xr and UNITY-xr, respectively (both from Markes Intl.). The GC separated the chemicals in the same way as explained previously. The separated chemicals were detected by TOF MS once they entered the TOF 'flight box'. TOF-MS separates fragment ions instead of molecular ions as in an IMS. The ions are detected depending upon the mass-to-charge ratio of the ions after passing through the drift tube [52,53].

For analysis, a thermal desorption (TD) sorbent tube (C2-AXXX-5149, Markes Intl., Llantrisant, UK) was inserted through the septum and into the headspace above the sample and then heated at $40{ }^{\circ} \mathrm{C}$ for $20 \mathrm{~min}$. A pump was then attached to the TD tube, and whilst still being heated to $40^{\circ} \mathrm{C}$, the headspace VOCs were then pulled onto the tubes at $20 \mathrm{~mL} /$ minute for a further $20 \mathrm{~min}$. The sorbent tubes were then placed in an autosampler for analysis. The analysis started with ULTRA-xr with a stand-by split set to $150{ }^{\circ} \mathrm{C}$. The GC run time for samples was $25 \mathrm{~min}$ with a programmed temperature ramp from $40{ }^{\circ} \mathrm{C}$ to $280{ }^{\circ} \mathrm{C}$ at $20{ }^{\circ} \mathrm{C} / \mathrm{min}$. Each sample was pre-purged for $1 \mathrm{~min}$ and then desorbed at $250{ }^{\circ} \mathrm{C}$ for $10 \mathrm{~min}$, with the trap purge time set to $1 \mathrm{~min}$. These traps were then cooled at $-30{ }^{\circ} \mathrm{C}$ and the trap was purged for $3 \mathrm{~min}$ at a temperature of $300^{\circ} \mathrm{C}$. The temperature for both transfer line and ion source were heated to $250^{\circ} \mathrm{C}$. The chemicals from GC-TOF-MS analysis were identified using the national institute of standards and technology (NIST) list (2011).

\subsection{Statistical Methods}

For GC-IMS data analysis, the data were extracted using the G.A.S VOCal (v0.1.3, G.A.S., Dortmund, Germany) software. This was followed by pre-processing steps to reduce the data's dimensionality. Among all the data points, the central section contained all the computationally significant chemical information and thus all the other data were removed through a cropping process. This was followed by applying a small threshold to remove the background information, which was a value just above the background noise level. The same data cropping and threshold values were used on all the data, and it was undertaken using an automated program. The data were then analysed using a 10-fold cross-validation, undertaken using a bespoke $\mathrm{R}$ program (version 3.6.2). Within each fold training set, feature selection was undertaken using a Wilcoxon rank-sum test between the different cancer groups and non-cancerous group. That resulted in the identification of the 20 most discriminatory features between the two groups and the features trained by three models, XGBoost, logistic regression, and random forest. The model was then applied to the test set to create class probabilities. Once all the samples had been within a test set, statistical 
results were generated from the probabilities, including a receiver operator characteristic (ROC) curve, area under the curve (AUC), sensitivity, specificity, positive predictive value (PPV), and negative predictive value (NPV).

An analogous approach was used for GC-TOF-MS data analysis. For GC-TOF-MS, the chemicals and the abundance of the chemicals were identified. Using the TOF-DS software, a background correction was applied, and the chromatogram was integrated, and the peaks were identified using the NIST list which was exported. The data obtained from GC-TOF-MS were converted into text files of chemical lists and abundances. The data were then processed using an ' $\mathrm{R}$ ' program that was like that used for GC-IMS, where chemical components of discriminative power were identified. Figure 1 provides a flow diagram of the data analysis steps.

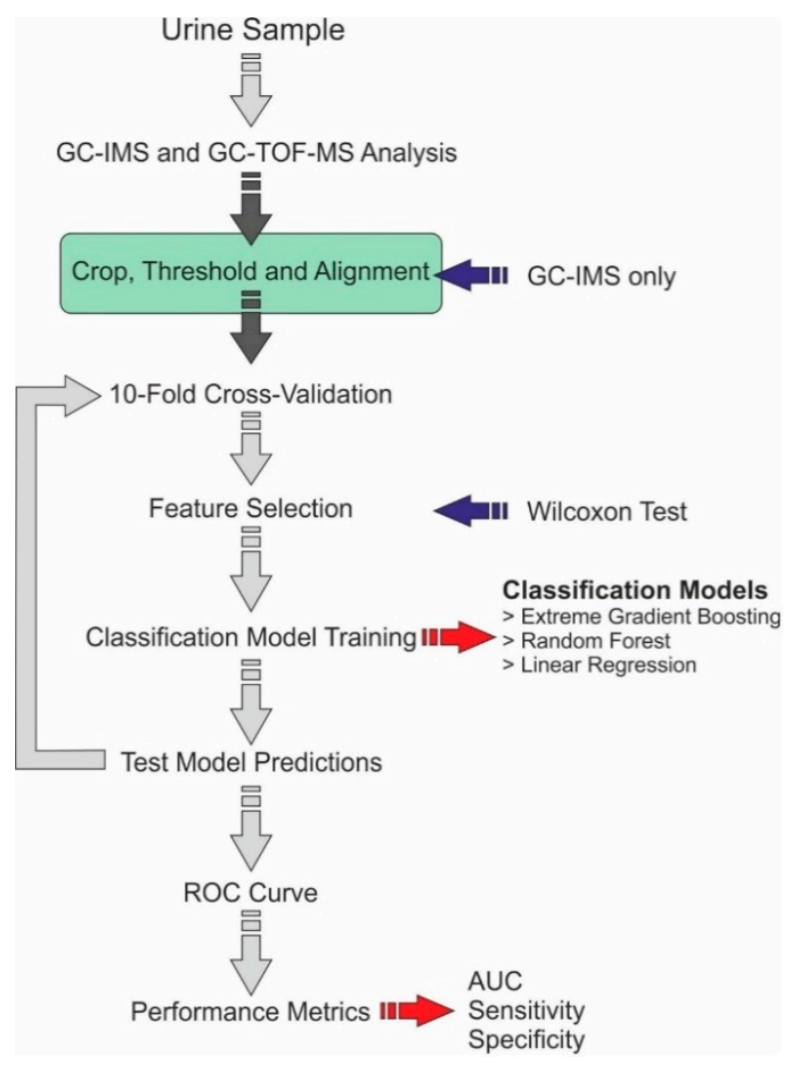

Figure 1. Data analysis pipeline.

\section{Results}

Figure 2 shows a typical output from the GC-IMS method from a urine sample in which the $x$-axis represents the drift time of the IMS and the $y$-axis represents the retention time of the GC. In the figure, the 'dots' are the chemicals detected by the IMS and the intensity of the peak represents the number of ions. Those 'dots' in red are the most intense. The red line in the figure is the default output of the instrument where no chemicals are present. G.A.S VOCal (v0.1.3, G.A.S., Dortmund, Germany) was used to view the GC-IMS data.

Figure 3 provides an example output from the GC-TOF-MS method. Here, the $x$-axis refers to the retention time, and the $y$-axis, the total ion count.

The results of the statistical analysis of the GC-IMS gathered results between different cancer groups and the non-cancerous group are given in Table 2 . The results demonstrate high sensitivity and specificity, indicating that there are significant differences between the VOC profiles of the different groups. Importantly, good separation between the two different cancers, $\mathrm{BCa}$ vs. $\mathrm{PCa}$, was also achieved. The false negative rate calculated for the GC-IMS analytical method in the study was 0.40 for BCa versus the PCa comparison, 
0.13 for BCa versus the non-cancerous group and 0.24 for PCa versus the non-cancerous group, whereas the false positive rate was 0.02 for $\mathrm{BCa}$ versus the $\mathrm{PCa}$ group, 0.08 for $\mathrm{BCa}$ versus the non-cancerous group and 0.12 for PCa versus the non-cancerous group.

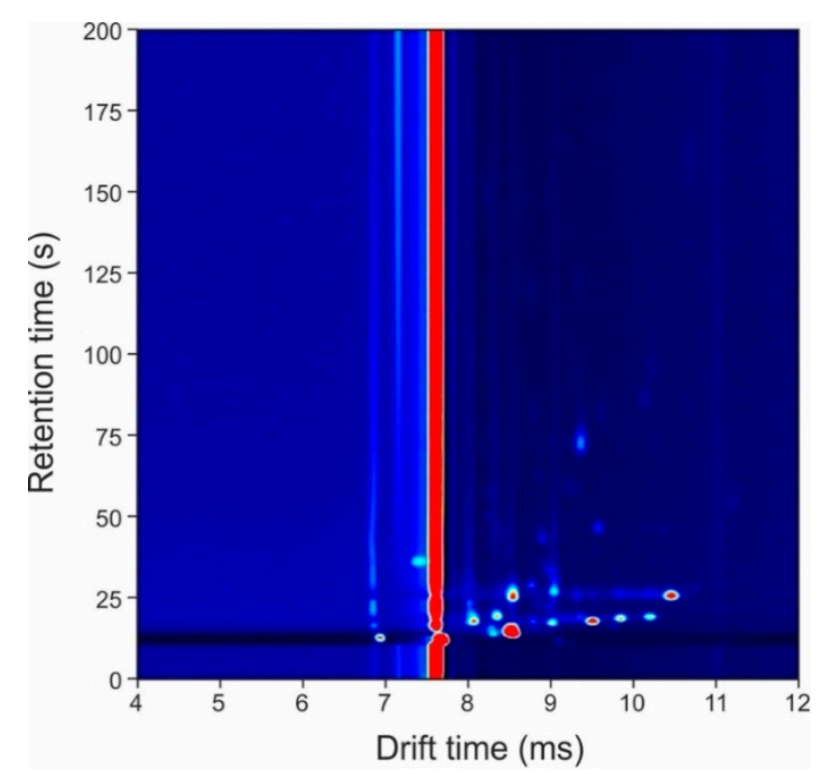

Figure 2. Typical output plot from the gas chromatography-ion mobility spectrometry (GC-IMS) instrument.

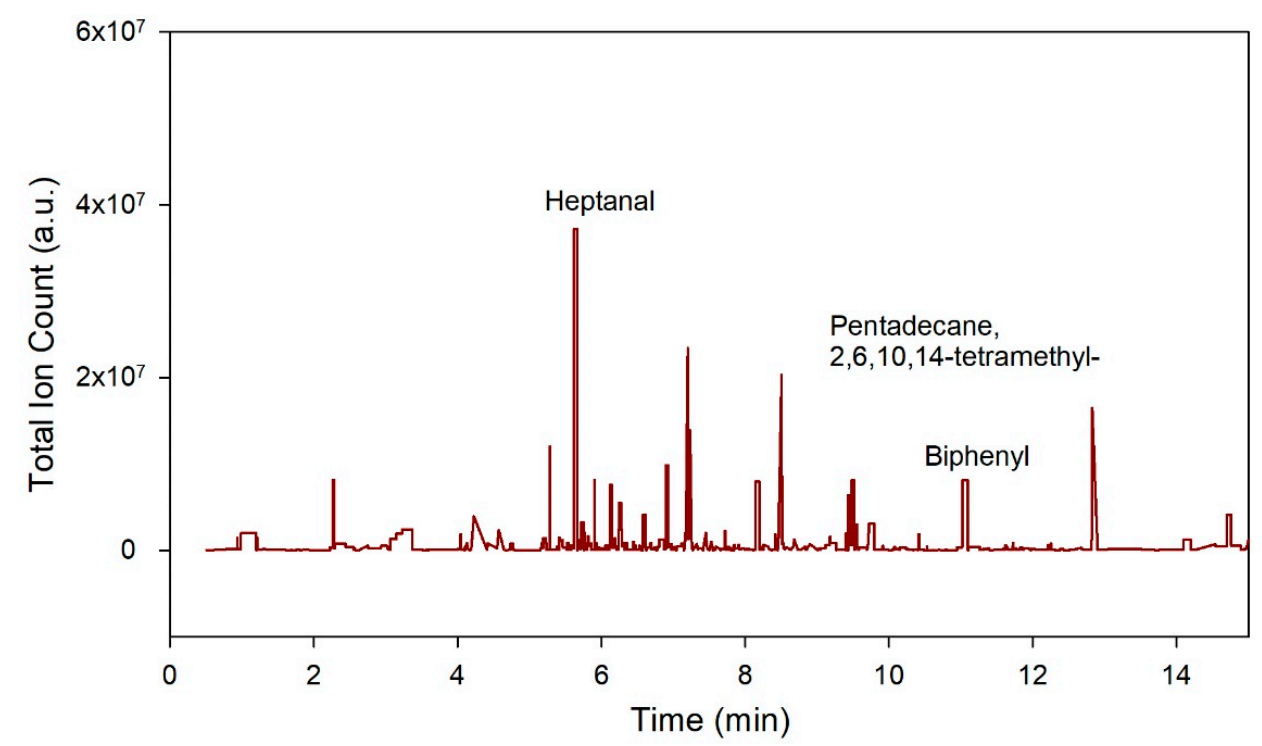

Figure 3. Figure illustrates a typical output plot of gas chromatography time-of-flight mass spectrometry (GC-TOF-MS). The $x$-axis in the plot represents the retention time and $y$-axis lists the chemical according to their abundance in the sample.

Table 2. GC-IMS diagnostic group results.

\begin{tabular}{|c|c|c|c|c|c|c|}
\hline Comparisons & Classifiers & AUC & Sensitivity & Specificity & PPV & NPV \\
\hline BCa vs. PCa & $\begin{array}{l}\text { Logistic Regression with } \\
\text { Elastic Net Regularization }\end{array}$ & $\begin{array}{c}0.97 \\
(0.93-1.00)\end{array}$ & $\begin{array}{c}0.60 \\
(0.38-0.80)\end{array}$ & $\begin{array}{c}0.98 \\
(0.95-1.00)\end{array}$ & 0.90 & 0.90 \\
\hline BCa vs. non-Cancerous & $\begin{array}{l}\text { Logistic Regression with } \\
\text { Elastic Net Regularization }\end{array}$ & $\begin{array}{c}0.95 \\
(0.90-0.99)\end{array}$ & $\begin{array}{c}0.87 \\
(0.70-1.00)\end{array}$ & $\begin{array}{c}0.92 \\
(0.84-0.98)\end{array}$ & 0.81 & 0.95 \\
\hline PCa vs. non-Cancerous & Extreme Gradient Boosting & $\begin{array}{c}0.89 \\
(0.83-0.94)\end{array}$ & $\begin{array}{c}0.76 \\
(0.64-0.88)\end{array}$ & $\begin{array}{c}0.88 \\
(0.80-0.95)\end{array}$ & 0.81 & 0.85 \\
\hline
\end{tabular}


The ROC curves obtained from GC-IMS data comparing BCa and the non-cancerous group, $\mathrm{BCa}$ and $\mathrm{PCa}$ groups, and $\mathrm{PCa}$ and non-cancerous groups are shown in Figure 4. The results indicate that among BCa patients and PCa patients, AUC (area under the curve) was $0.97(0.93-1.00)$ with sensitivity and specificity of $0.60(0.38-0.80)$ and $0.98(0.95-1.00)$, respectively. However, the separation between $\mathrm{BCa}$ and non-cancerous samples was even higher with a sensitivity of $0.87(0.70-1.00)$, specificity of $0.92(0.84-0.98)$ and AUC of 0.95 (0.90-0.99). Similarly, for PCa vs non-cancerous samples using GC-IMS, the separation was significant with a sensitivity of $0.76(0.64-0.88)$, specificity of $0.88(0.80-0.95)$ and AUC of $0.89(0.83-0.94)$.

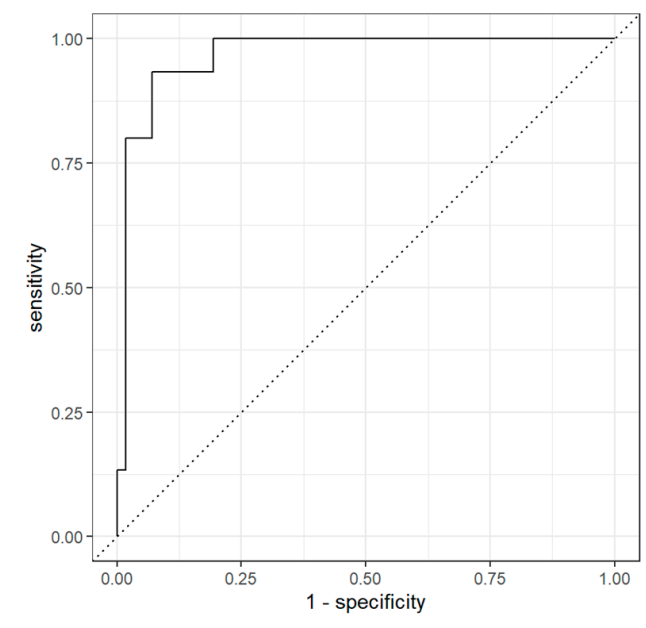

(a)

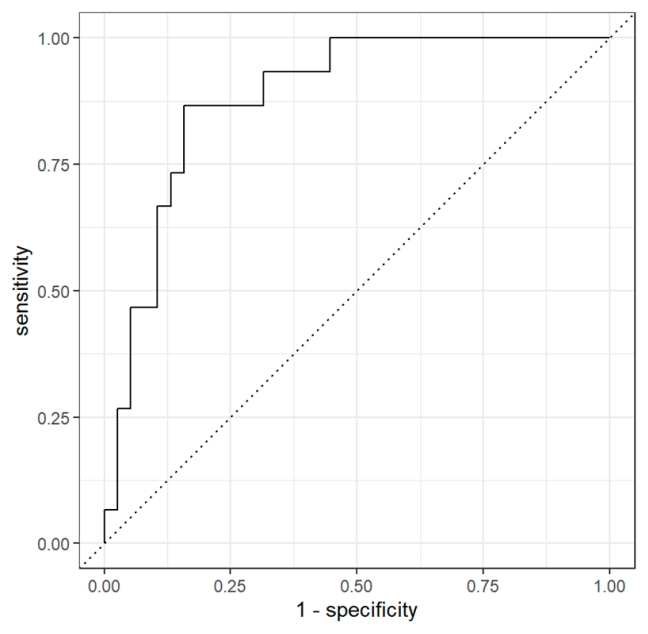

(b)

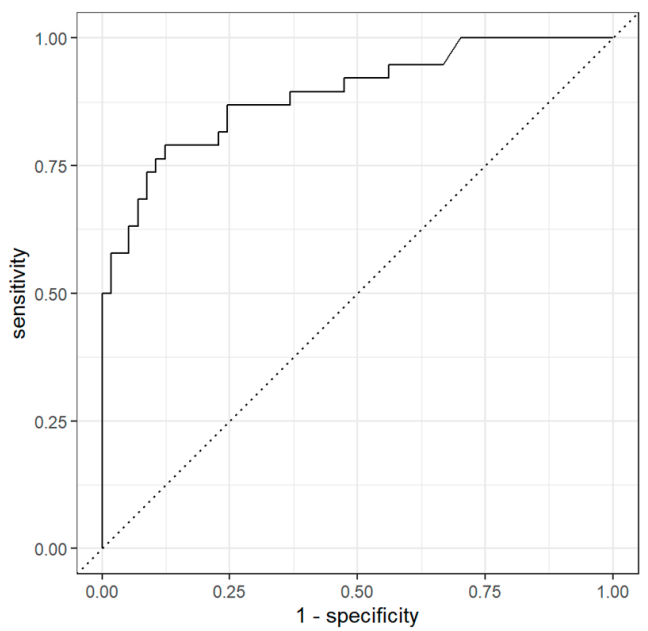

(c)

Figure 4. Receiver operator characteristic for (a) bladder cancer vs. PCa; (b) bladder cancer vs. non-cancerous group; and (c) prostate cancer vs. non-cancerous group using GC-IMS.

The results of the statistical analysis between different cancer groups for GC-TOF-IMS are given in Table 3. The results demonstrate high sensitivity and specificity, indicating that there are significant differences between the VOC profiles of different cancer groups, which was also shown in the GC-IMS data. The results showed that the false negative rate for BCa versus PCa comparison was 0.47 , for BCa versus the non-cancerous group was 0.73 and for PCa versus the non-cancerous group was 0.22 for the GC-TOF-MS analytical method. The false positive rate for BCa versus PCa comparison was 0.1 , for BCa versus the non-cancerous group it was 0.06 , and for PCa versus the non-cancerous group it was 0.12. 
Table 3. GC-TOF-MS diagnostic group results.

\begin{tabular}{|c|c|c|c|c|c|c|}
\hline Comparisons & Classifiers & AUC & Sensitivity & Specificity & PPV & NPV \\
\hline BCa vs. PCa & $\begin{array}{l}\text { Logistic Regression with } \\
\text { Elastic Net Regularization }\end{array}$ & $\begin{array}{c}0.84 \\
(0.73-0.93)\end{array}$ & $\begin{array}{c}0.53 \\
(0.33-0.75)\end{array}$ & $\begin{array}{c}0.90 \\
(0.83-0.96)\end{array}$ & 0.62 & 0.87 \\
\hline BCa vs. non-Cancerous & Random Forest & $\begin{array}{c}0.81 \\
(0.70-0.90)\end{array}$ & $\begin{array}{c}0.27 \\
(0.09-0.46)\end{array}$ & $\begin{array}{c}0.94 \\
(0.88-1.00)\end{array}$ & 0.33 & 0.71 \\
\hline PCa vs. Non-Cancerous & Random Forest & $\begin{array}{c}0.94 \\
(0.90-0.97)\end{array}$ & $\begin{array}{c}0.78 \\
(0.66-0.89)\end{array}$ & $\begin{array}{c}0.88 \\
(0.80-0.95)\end{array}$ & 0.82 & 0.85 \\
\hline
\end{tabular}

The ROC curves obtained from GC-TOF-MS data comparing BCa and non-cancerous groups, BCa and PCa groups, and PCa and non-cancerous groups are shown in Figure 5. The results indicate that GC-TOF-MS was able to differentiate BCa and PCa with AUC $0.84(0.73-0.93)$, sensitivity and specificity of $0.53(0.33-0.75)$ and $0.90(0.83-0.96)$. The separation between $\mathrm{BCa}$ and non-cancerous samples was very poor with sensitivity only 0.27 (0.9-0.46), specificity $0.94(0.88-1.00)$ and AUC 0.82 (0.72-0.90). However, the separation was more significant with sensitivity $0.78(0.66-0.89)$, specificity $0.88(0.80-0.95)$ and AUC 0.94 (0.90-0.97) for PCa and non-cancerous groups.

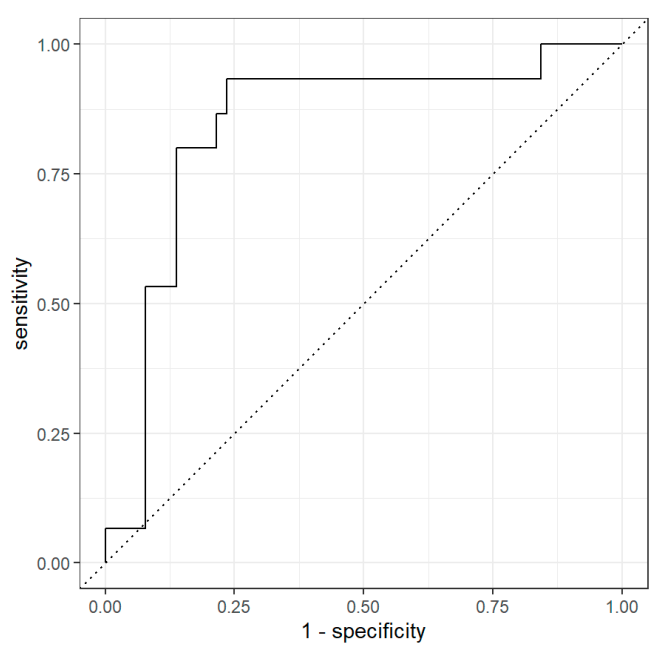

(a)

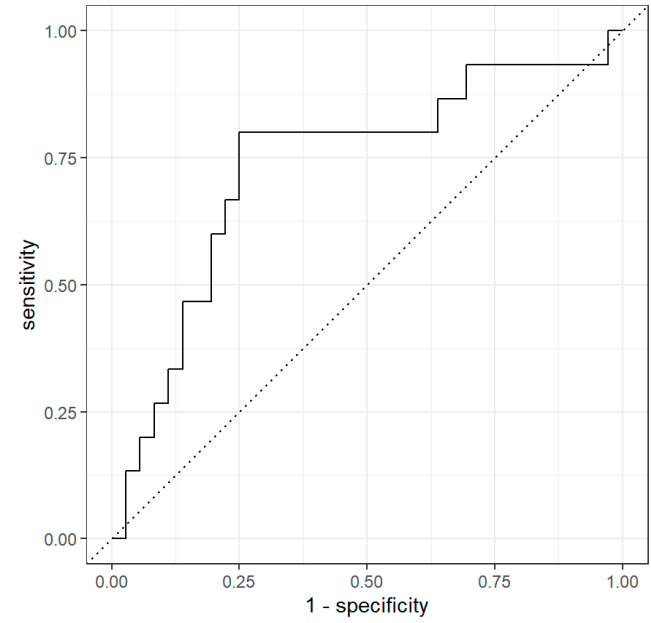

(b)

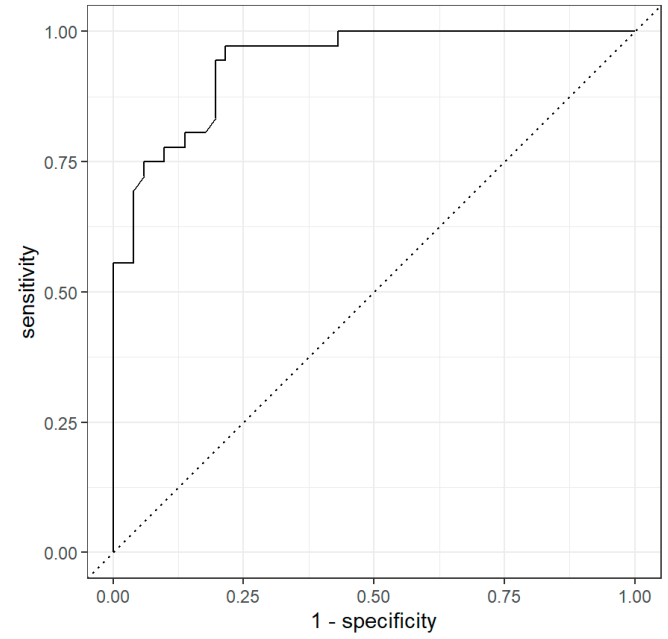

(c)

Figure 5. ROC for (a) bladder cancer vs. PCa; (b) bladder cancer vs. non-cancerous group; and (c) prostate cancer vs. non-cancerous group using GC-TOF-MS. 
In our results, we analysed different VOCs linked to BCa and PCa for the screening and diagnosis of these cancers. A total of 34 biomarkers were found using TOF-DS software. These VOCs were verified using PubChem, NIST (National Institute of Standards and Technology), and previously published papers. Out of 34, 13 VOCs were found in the comparison of BCa and non-cancerous groups specific to BCa, as shown in Table 4, seven in PCa and non-cancerous groups specific to PCa, as shown in Table 5, and 14 VOCs were found in the comparison of BCa and PCa group, as shown in Table 6, out of which 3 VOCs do not overlap either with $\mathrm{BCa}$ or $\mathrm{PCa}$, which may indicate that they are new markers.

Table 4. A list of possible biomarkers from the analysis of urine samples by GC-TOF-MS identified using PubChem, NIST and publications significant to bladder cancer.

\begin{tabular}{cccc}
\hline & Chemicals & $p$-Values & Molecular Weight (g/mol) \\
\hline 1 & Biphenyl & $<0.01$ & 154.21 \\
2 & Nonanal & $<0.01$ & 142.24 \\
3 & Tetradecane & $<0.01$ & 198.39 \\
4 & Pentadecane, 2,6,10,14-tetramethyl- & 0.012 & 268.5 \\
5 & 2-Pentanone & 0.012 & 86.13 \\
6 & Undecane & 0.014 & 156.31 \\
7 & 4-Heptanone & 0.018 & 114.19 \\
8 & Dodecane & 0.025 & 170.33 \\
9 & Hexadecane & 0.026 & 226.44 \\
10 & Heptanal & 0.026 & 114.19 \\
11 & Methyl Isobutyl Ketone & 0.045 & 100.16 \\
12 & Naphthalene & 0.046 & 128.169 \\
13 & Benzoic acid & 0.049 & 122.12 \\
\hline
\end{tabular}

Table 5. List of possible biomarkers from the analysis of urine samples by GC-TOF-MS identified using PubChem, NIST and publications significant to PCa.

\begin{tabular}{cccc}
\hline & Chemicals & $p$-Values & Molecular Weight (g/mol) \\
\hline 1 & Toluene & $<0.01$ & 92.14 \\
2 & Phenol & $<0.01$ & 325.4 \\
3 & Acetic acid & $<0.01$ & 60.05 \\
4 & 1-Hexanol, 2-ethyl- & 0.011 & 130.229 \\
5 & Disulfide, dimethyl & 0.012 & 94.2 \\
6 & Cyclopentanone, 2-methyl- & 0.017 & 98.14 \\
7 & Pyrrole & 0.033 & 67.09 \\
\hline
\end{tabular}

Table 6. List of possible biomarkers from the analysis of urine samples by GC-TOF-MS identified using PubChem, NIST and publications significant to PCa and bladder cancer.

\begin{tabular}{cccc}
\hline & Chemicals & $p$-Values & Molecular Weight (g/mol) \\
\hline 1 & Toluene & $<0.01$ & 92.14 \\
2 & Methyl Isobutyl Ketone & $<0.01$ & 100.16 \\
3 & Dodecane & $<0.01$ & 170.33 \\
4 & Phenol & $<0.01$ & 325.4 \\
5 & Cyclopentanone, 2-methyl- & $<0.01$ & 98.14 \\
6 & 2-Hexanone & $<0.01$ & 100.16 \\
7 & Heptanal & $<0.01$ & 114.19 \\
8 & p-Xylene & $<0.01$ & 106.16 \\
9 & Nonane, 3-methyl- & $<0.01$ & 142.28 \\
10 & Tetradecane & $<0.01$ & 198.39 \\
11 & Nonanal & $<0.01$ & 142.24 \\
12 & Biphenyl & 0.019 & 154.21 \\
13 & Acetic acid & 0.025 & 60.05 \\
14 & 2-Pentanone & 0.032 & 86.13 \\
\hline
\end{tabular}




\section{Discussion}

In our study, we found that both GC-IMS and GC-TOF-MS were able to separate different cancer groups from each other as well as non-cancerous group. The separation between BCa from non-cancerous group was highest using GC-IMS with 0.95 AUC (0.87 sensitivity and 0.92 specificity). A similar study conducted by Weber et al. [54] suggested overall accuracy of $70 \%$ (70\% sensitivity and $70 \%$ specificity) using urinary headspace for the analysis of BCa using gas sensors. Another study conducted by Khalid et al. [55] showed very high statistical results using an in-house GC-sensor device. They used two models for analysis suggesting $100 \%$ sensitivity and $94.6 \%$ specificity using a linear discriminant analysis (LDA) model and $95.8 \%$ sensitivity and $94.6 \%$ specificity using PLS-DA.

The separation between PCa and the non-cancerous group was highest using GC-TOF-MS method with 0.94 AUC ( 0.78 sensitivity and 0.88 specificity) whereas the study conducted by Gao et al. [56] for the analysis of urinary VOCs for prostate cancer calculated 0.92 AUC (0.96 sensitivity and 0.80 specificity). Another study conducted by Lima et al. [57] used PLS-DA to discriminate PCa from non-cancerous group with an AUC of 0.83 ( $84 \%$ sensitivity and $80 \%$ specificity) using urine headspace.

In this study, we developed urinary VOC profiles linked with BCa and PCa. Table 4 consists of the chemicals that have been identified in our study and have been cross verified using PubChem, NIST and previously published research, which may have relevance to $\mathrm{BCa}$ diagnosis.

Out of 13 VOCs found to be noteworthy to BCa, biphenyl, heptanal, and 2,6,10, 14-tetramethyl-pentadecane were the three distinct biomarkers found in our study that did not overlap with other studies. Biphenyl has been identified as the most significant biomarker in our study. Biphenyl has been linked to various diseases, including carcinoma. It has been proven that biphenyl is a promoter of BCa in rats [58]. Biphenyl has been found to be metabolized in the liver [59]. Heptanal is reported to present in the blood of lung cancer patients [60]. According to the HMBD (Human Metabolome Database), the biological activity of heptanal inside humans can cause digestive disorder including associated with the bladder [61]. 2,6,10,14-tetramethyl-pentadecane is reported as carcinogens but is mentioned far less in the literature [62]. Nonanal, tetradecane, dodecane, hexadecane, naphthalene, and methyl isobutyl ketone were suggested by Rodrigues et al. [63] in their study using GC-MS on BCa cell lines whereas 2-pentanone and 4-heptanone overlap with the findings of Cauchi et al. [29]. Benzoic acid was another chemical found in our study that overlapped in both Rodrigues et al. [63] and Cauchi et al. [29].

From the analysis of PCa urine samples, a total of seven distinct VOCs were identified and are summarised in Table 5. In our study, we found toluene as the most significant chemical for PCa. Toluene has been published previously as a significant biomarker for PCa [64]. In addition, it has been reported that toluene has been found to be associated with testicular diseases $[65,66]$. Pyrrole has been reported by Smith et al. in their study with 24 controls and 13 patients with PCa. They tested the urine samples to assess VOC profiles and found pyrrole to be one of the significant markers for PCa [67]. 2-Ethyl-1-hexanol, phenol and dimethyl disulphide [68], acetic acid [69], and 2-methyl cyclopentanone [70] were also found in our study, which overlaps with previous studies.

Table 6 represents all the chemicals found in the analysis of urine samples for prostate versus BCa. Most of the chemicals present in this list are like those found in Tables 4 and 5. 2-Hexanone, p-xylene, and 3-methyl nonane are the only significant chemicals out of 14 in this list that are important for separating BCa and PCa. 2-Hexanone and p-xylene have previously been reported as significant markers for the $\mathrm{PCa}[68,70]$. There is no significant evidence for both 2-hexanone and p-xylene as a potential biomarker for BCa. However, 3-methyl-Nonane has not yet been reported as a biomarker for either bladder or PCa, although they have been reported as a biomarker for lung cancer in different studies [71,72]. This may signify the importance of 3-methyl-nonane as a potentially significant marker. The results reported in this paper support the findings of other groups for the validation of these chemicals as potential biomarkers in both PCa and BCa. It has been noted that 
the chemicals found in all the cancer groups were different and there was almost no overlapping of the VOC fingerprints for BCa and PCa. This adds further support to the unique VOC fingerprint in cancers of different cell origins [73].

The use of urinary VOC analysis is an attractive option due to the non-invasive nature. It also has the potential to be used in early cancer diagnosis with further validation studies. This approach may also prove to be efficient, whilst lowering the cost per patient, and increasing patient compliance due to its non-invasive nature. The results of using GC-IMS as an analysis tool are significant as the method is much simpler than using a high-end analytical method, such as GC-MS, and without the need for a laboratory environment. We believe that using VOCs to analyse human waste will be an important diagnostic tool for the future. Cancer may well be one area of focus and may be used as part of the UK 2 -week wait screening program to help reduce the number of unneeded procedures. The key is to run more larger studies targeting these cancers and to have tools that are $\mathrm{CE}$ marked (or equivalent) for cancer diagnosis. We plan to use urine VOCs in association with other tests in future which help to improve the performance and achieve a more in depth understanding of VOCs and their metabolic pathways.

Our results were limited by not accounting for the contributory factors that can also lead to abnormal metabolism with subsequent excretion of differing concentrations of these chemicals in the urine. These factors include stress, alcohol, smoking, certain food products, medicines, and different environmental factors. Several studies have reported the effect of smoking on VOCs $[74,75]$. Study conducted by A. McWilliams et al. showed that active smoking had an impact on urinary VOC profiles associated with current smokers and ex-smokers [76]. We aim to consider these further in the next study. We also did not undertake full chemical identification with calibration standards. However, many of the chemicals we found correlate with other studies and, therefore, there is evidence that these are correct.

\section{Conclusions}

In this paper, GC-IMS and GC-TOF-MS methods were used to identify VOC fingerprints using urine headspace and establish an interdependence between $\mathrm{BCa}, \mathrm{PCa}$ and non-cancerous samples. It was found that both GC-IMS and GC-TOF-MS have the potential to differentiate between different cancer groups with respective AUC for different diagnostic groups: For GC-IMS, BCa and PCa (0.97 (0.93-1)), BCa and non-cancerous (0.95 (0.90-0.99)), PCa and non-cancerous (0.89 (0.83-0.94)) and for GC-TOF-MS, BCa and PCa $(0.84(0.73-0.93)), \mathrm{BCa}$ and non-cancerous $(0.81(0.70-0.90))$, PCa and non-cancerous $(0.94(0.90-0.97))$. A total of 35 VOCs were found to be relevant for identifying these cancer groups, with several VOCs distinct to each cancer. VOCs from this study were supported by findings from previous studies. This signifies that VOCs for both bladder and prostate cancer have different profiles, which may be helpful in future to distinguish them. In the future, the VOC profiles obtained from these analytical devices can be used as a reference for developing low-cost devices. It is plausible that VOC profiles can be used as an adjunct to diagnosis enabling selection of only high-risk groups to undergo cystoscopy examinations which will be widely beneficial considering limited capacity and cost.

Author Contributions: Conceptualization, H.T., E.D. and J.A.C.; methodology, H.T. and E.D.; formal analysis, H.T.; investigation, H.T.; resources, J.A.C. and R.P.A.; data curation, H.T. and A.S.B.; writing-original draft preparation, H.T.; writing—review and editing, H.T., E.D., A.S.B. and J.A.C. and R.P.A.; visualization, H.T. and J.A.C.; supervision, J.A.C.; project administration, J.A.C. and R.P.A. All authors have read and agreed to the published version of the manuscript.

Funding: This research received no external funding.

Institutional Review Board Statement: This study was approved by Coventry and Warwickshire and North-East Yorkshire NHS Ethics Committees (Ref 18717 and Ref 260179).

Informed Consent Statement: Informed consent was obtained from all subjects involved in the study. Written informed consent has been obtained from the patient(s) to publish this paper. 
Data Availability Statement: The data presented in this study are available on request from the corresponding author. The data are not publicly available due to the ethical approval.

Conflicts of Interest: The authors declare no conflict of interest.

\section{References}

1. Ott, J.J.; Ullrich, A.; Miller, A.B. The importance of early symptom recognition in the context of early detection and cancer survival. Eur. J. Cancer 2009, 45, 2743-2748. [CrossRef]

2. de Nooijer, J.; Lechner, L.; de Vries, H. Early detection of cancer: Knowledge and behavior among Dutch adults. Cancer Detect. Prev. 2002, 26, 362-369. [CrossRef]

3. Bloom, J.R. Early detection of cancer. Psychologic and social dimensions. Cancer 1994, 74, 1464-1473. [CrossRef]

4. McPhail, S.D.; Johnson, S.T.; Greenberg, D.S.; Peake, M.D.; Rous, B. Stage at diagnosis and early mortality from cancer in England. Br. J. Cancer 2015, 112, S108-S115. [CrossRef]

5. Sung, H.; Ferlay, J.; Siegel, R.L.; Laversanne, M.; Soerjomataram, I.; Jemal, A.; Bray, F. Global cancer statistics 2020: GLOBOCAN estimates of incidence and mortality worldwide for 36 cancers in 185 countries. CA A Cancer J. Clin. 2021, 71, 209-249. [CrossRef] [PubMed]

6. Bray, F.; Ferlay, J.; Soerjomataram, I.; Siegel, R.L.; Torre, L.A.; Jemal, A.E. Global cancer statistics 2018: GLOBOCAN estimates of incidence and mortality worldwide for 36 cancers in 185 countries. CA A Cancer J. Clin. 2018, 68, 394-424. [CrossRef] [PubMed]

7. Richards, M.A. The size of the prize for earlier diagnosis of cancer in England. Br. J. Cancer 2009, 101, S125-S129. [CrossRef]

8. Saginala, K.; Barsouk, A.; Aluru, J.S.; Rawla, P.; Padala, S.A.; Barsouk, A. Epidemiology of Bladder Cancer. Med. Sci. 2020, 8, 15. [CrossRef]

9. Richters, A.; Aben, K.K.H.; Kiemeney, L.A.L.M. The global burden of urinary bladder cancer: An update. World J. Urol. 2019, 38, 1895-1904. [CrossRef]

10. Yafi, F.A.; Brimo, F.; Steinberg, J.; Aprikian, A.G.; Tanguay, S.; Kassouf, W. Prospective analysis of sensitivity and specificity of urinary cytology and other urinary biomarkers for bladder cancer. Urol. Oncol. Semin. Orig. Investig. 2015, 33, 66.e25-66.e31. [CrossRef]

11. Planz, B.; Jochims, E.; Deix, T.; Caspers, H.P.; Jakse, G.; Boecking, A. The role of urinary cytology for detection of bladder cancer. Eur. J. Surg. Oncol. (EJSO) 2005, 31, 304-308. [CrossRef]

12. Kumar, N.; Talwar, R.; Nandy, P.R. Efficacy of voided urinary cytology and ultrasonography compared to cystoscopy in the detection of urinary bladder cancer. Afr. J. Urol. 2017, 23, 192-196. [CrossRef]

13. Budman, L.I.; Kassouf, W.; Steinberg, J.R. Biomarkers for detection and surveillance of bladder cancer. Can. Urol. Assoc. J. 2013, 2, 212-221. [CrossRef] [PubMed]

14. Culp, M.B.; Soerjomataram, I.; Efstathiou, J.A.; Bray, F.; Jemal, A. Recent Global Patterns in Prostate Cancer Incidence and Mortality Rates. Eur. Urol. 2019, 77, 38-52. [CrossRef] [PubMed]

15. Bleyer, A.; Spreafico, F.; Barr, R. Prostate cancer in young men: An emerging young adult and older adolescent challenge. Cancer 2020, 126, 46-57. [CrossRef]

16. Deev, V.; Solovieva, S.; Andreev, E.; Protoshchak, V.; Karpushchenko, E.; Sleptsov, A.; Kartsova, L.; Bessonova, E.; Legin, A.; Kirsanov, D. Prostate cancer screening using chemometric processing of GC-MS profiles obtained in the headspace above urine samples. J. Chromatogr. B 2020, 1155, 122298. [CrossRef]

17. van den Bergh, R.C.N.; Roemeling, S.; Roobol, M.J.; Roobol, W.; Schröder, F.H.; Bangma, C.H. Prospective Validation of Active Surveillance in Prostate Cancer: The PRIAS Study. Eur. Urol. 2007, 52, 1560-1563. [CrossRef]

18. Catalona, W.J.; Smith, D.S.; Ratliff, T.L.; Dodds, K.M.; Coplen, D.E.; Yuan, J.J.; Petros, J.A.; Andriole, G.L. Measurement of Prostate-Specific Antigen in Serum as a Screening Test for Prostate Cancer. N. Engl. J. Med. 1991, 324, 1156-1161. [CrossRef]

19. Schröder, F.H.; Hugosson, J.; Roobol, M.J.; Tammela, T.L.J.; Ciatto, S.; Nelen, V.; Kwiatkowski, M.; Lujan, M.; Lilja, H.; Zappa, M.; et al. Screening and Prostate-Cancer Mortality in a Randomized European Study. N. Engl. J. Med. 2009, 360, 1320-1328. [CrossRef] [PubMed]

20. Rosario, D.J.; Lane, J.A.; Metcalfe, C.; Donovan, J.L.; Doble, A.; Goodwin, L.; Davis, M.; Catto, J.W.F.; Avery, K.; Neal, D.E.; et al. Short term outcomes of prostate biopsy in men tested for cancer by prostate specific antigen: Prospective evaluation within ProtecT study. BMJ 2012, 344, d7894. [CrossRef]

21. Wade, J.; Rosario, D.J.; Macefield, R.C.; Avery, K.N.; Salter, C.E.; Goodwin, M.L.; Blazeby, J.M.; Lane, J.A.; Metcalfe, C.; Neal, D.E. Psychological impact of prostate biopsy: Physical symptoms, anxiety, and depression. J. Clin. Oncol. 2013, 31, 4235-4241. [CrossRef]

22. Mottet, N.; Bellmunt, J.; Bolla, M.; Briers, E.; Cumberbatch, M.G.; De Santis, M.; Fossati, N.; Gross, T.; Henry, A.M.; Joniau, S.; et al. EAU-ESTRO-SIOG Guidelines on Prostate Cancer. Part 1: Screening, Diagnosis, and Local Treatment with Curative Intent. Eur. Urol. 2017, 71, 618-629. [CrossRef]

23. Williams, H.; Pembroke, A. Sniffer dogs in the melanoma clinic? Lancet 1989, 333, 734. [CrossRef]

24. Chang, J.-E.; Lee, D.-S.; Ban, S.-W.; Oh, J.; Jung, M.Y.; Kim, S.-H.; Park, S.; Persaud, K.; Jheon, S. Analysis of volatile organic compounds in exhaled breath for lung cancer diagnosis using a sensor system. Sensors Actuators B Chem. 2018, 255, 800-807. [CrossRef] 
25. Bond, A.; Greenwood, R.; Lewis, S.; Corfe, B.; Sarkar, S.; O’Toole, P.; Rooney, P.; Burkitt, M.; Hold, G.; Probert, C. Volatile organic compounds emitted from faeces as a biomarker for colorectal cancer. Aliment. Pharmacol. Ther. 2019, 49, 1005-1012. [CrossRef]

26. Arasaradnam, R.P.; Wicaksono, A.; O’Brien, H.; Kocher, H.M.; Covington, J.A.; Crnogorac-Jurcevic, T. Noninvasive diagnosis of pancreatic cancer through detection of volatile organic compounds in urine. Gastroenterology 2018, 154, 485-487. [CrossRef] [PubMed]

27. Staff, P.O. Correction: Detection of Colorectal Cancer (CRC) by Urinary Volatile Organic Compound Analysis. PLoS ONE 2015, 10, e0118975.

28. Becker, R. Non-invasive cancer detection using volatile biomarkers: Is urine superior to breath? Med. Hypotheses 2020, 143, 110060. [CrossRef]

29. Cauchi, M.; Weber, C.M.; Bolt, B.J.; Spratt, P.B.; Bessant, C.; Turner, D.C.; Willis, C.M.; Britton, L.E.; Turner, C.; Morgan, G. Evaluation of gas chromatography mass spectrometry and pattern recognition for the identification of bladder cancer from urine headspace. Anal. Methods 2016, 8, 4037-4046. [CrossRef]

30. Renshaw, A.A.; Nappi, D.; Weinberg, D.S. Cytology of Grade 1 Papillary Transitional Cell Carcinoma. Acta Cytol. 1996, 40, 676-682. [CrossRef] [PubMed]

31. Raab, S.S.; Grzybicki, D.M.; Vrbin, C.M.; Geisinger, K.R. Urine cytology discrepancies: Frequency, causes, and outcomes. Am. J. Clin. Pathol. 2007, 127, 946-953. [CrossRef]

32. Muus Ubago, J.; Mehta, V.; Wojcik, E.M.; Barkan, G.A. Evaluation of atypical urine cytology progression to malignancy. Cancer Cytopathol. 2013, 121, 387-391. [CrossRef]

33. Chang, K.L.; Ho, P.C. Gas Chromatography Time-Of-Flight Mass Spectrometry (GC-TOF-MS)-Based Metabolomics for Comparison of Caffeinated and Decaffeinated Coffee and Its Implications for Alzheimer's Disease. PLoS ONE 2014, 9, e104621. [CrossRef]

34. Rudnicka, J.; Kowalkowski, T.; Ligor, T.; Buszewski, B. Determination of volatile organic compounds as biomarkers of lung cancer by SPME-GC-TOF/MS and chemometrics. J. Chromatogr. B 2011, 879, 3360-3366. [CrossRef]

35. Tiele, A.; Wicaksono, A.; Daulton, E.; Ifeachor, E.; Eyre, V.; Clarke, S.; Timings, L.; Pearson, S.; Covington, J.A.; Li, X. Breath-based non-invasive diagnosis of Alzheimer's disease: A pilot study. J. Breath Res. 2020, 14, 26003. [CrossRef]

36. Bosch, S.; Bot, R.; Wicaksono, A.; Savelkoul, E.; van der Hulst, R.; Kuijvenhoven, J.; Stokkers, P.; Daulton, E.; Covington, J.A.; de Meij, T.G.J.; et al. Early detection and follow-up of colorectal neoplasia based on faecal volatile organic compounds. Colorectal Dis. 2020, 22, 1119-1129. [CrossRef]

37. Esfahani, S.; Sagar, N.M.; Kyrou, I.; Mozdiak, E.; O'Connell, N.; Nwokolo, C.; Bardhan, K.D.; Arasaradnam, R.P.; Covington, J.A. Variation in Gas and Volatile Compound Emissions from Human Urine as It Ages, Measured by an Electronic Nose. Biosensors 2016, 6, 4. [CrossRef] [PubMed]

38. Epstein, J.I.; Egevad, L.; Amin, M.B.; Delahunt, B.; Srigley, J.R.; Humphrey, P.A. The 2014 International Society of Urological Pathology (ISUP) consensus conference on Gleason grading of prostatic carcinoma. Am. J. Surg. Pathol. 2016, 40, $244-252$. [CrossRef] [PubMed]

39. Mostofi, F.K. Histological typing of urinary bladder tumors. Int. Histol. Classif. Tumors 1973, 17. Available online: https://apps.who. int/iris/handle/10665/41533 (accessed on 16 October 2021).

40. Haley, L.V.; Romeskie, J.M. Development of an explosives detection system using fast GC-IMS technology. In Proceedings of the IEEE 32nd Annual 1998 International Carnahan Conference on Security Technology (Cat. No.98CH36209), Alexandria, VA, USA, 12-14 October 1998; pp. 59-64. [CrossRef]

41. Cook, G.W.; LaPuma, P.T.; Hook, G.L.; Eckenrode, B.A. Using Gas Chromatography with Ion Mobility Spectrometry to Resolve Explosive Compounds in the Presence of Interferents*. J. Forensic Sci. 2010, 55, 1582-1591. [CrossRef]

42. Kwan, C.; Snyder, A.P.; Erickson, R.P.; Smith, P.A.; Maswadeh, W.M.; Ayhan, B.; Jensen, J.L.; Jensen, J.O.; Tripathi, A. Chemical Agent Detection Using GC-IMS: A Comparative Study. IEEE Sensors J. 2010, 10, 451-460. [CrossRef]

43. Moura, P.C.; Vassilenko, V.; Fernandes, J.M.; Santos, P.H. Indoor and Outdoor Air Profiling with GC-IMS. In Doctoral Conference on Computing, Electrical and Industrial Systems; Springer: Berlin/Heidelberg, Germany, 2020.

44. Allers, M.; Langejuergen, J.; Gaida, A.; Holz, O.; Schuchardt, S.; Hohlfeld, J.M.; Zimmermann, S. Measurement of exhaled volatile organic compounds from patients with chronic obstructive pulmonary disease (COPD) using closed gas loop GC-IMS and GC-APCI-MS. J. Breath Res. 2016, 10, 26004. [CrossRef]

45. Tiele, A.; Wicaksono, A.; Kansara, J.; Arasaradnam, R.P.; Covington, J.A. Breath Analysis Using eNose and Ion Mobility Technology to Diagnose Inflammatory Bowel Disease-A Pilot Study. Biosensors 2019, 9, 55. [CrossRef] [PubMed]

46. Rouvroye, M.D.; Wicaksono, A.; Bosch, S.; Savelkoul, E.; Covington, J.A.; Beaumont, H.; Mulder, C.J.; Bouma, G.; de Meij, T.G.J.; de Boer, N.K.H. Faecal Scent as a Novel Non-Invasive Biomarker to Discriminate between Coeliac Disease and Refractory Coeliac Disease: A Proof of Principle Study. Biosensors 2019, 9, 69. [CrossRef] [PubMed]

47. Valli, E.; Panni, F.; Casadei, E.; Barbieri, S.; Cevoli, C.; Bendini, A.; García-González, D.L.; Gallina Toschi, T. An HS-GC-IMS Method for the Quality Classification of Virgin Olive Oils as Screening Support for the Panel Test. Foods 2020, 9, 657. [CrossRef] [PubMed]

48. Wang, S.; Chen, H.; Sun, B. Recent progress in food flavor analysis using gas chromatography-ion mobility spectrometry (GC-IMS). Food Chem. 2020, 315, 126158. [CrossRef] 
49. Zhang, X.; Dai, Z.; Fan, X.; Liu, M.; Ma, J.; Shang, W.; Liu, J.; Strappe, P.; Blanchard, C.; Zhou, Z. A study on volatile metabolites screening by HS-SPME-GC-MS and HS-GC-IMS for discrimination and characterization of white and yellowed rice. Cereal Chem. 2020, 97, 496-504. [CrossRef]

50. Haley, L.V.; Romeskie, J.M. GC-IMS: A technology for many applications. Proc. SPIE 1998, 3575, 375-383. [CrossRef]

51. Kanu, A.B.; Hill, H.H. Ion mobility spectrometry detection for gas chromatography. J. Chromatogr. A 2008, 1177, 12-27. [CrossRef]

52. Denawaka, C.J.; Fowlis, I.A.; Dean, J.R. Evaluation and application of static headspace-multicapillary column-gas chromatography-ion mobility spectrometry for complex sample analysis. J. Chromatogr. A 2014, 1338, 136-148. [CrossRef] [PubMed]

53. Ferrer, I.; Thurman, E.M. Liquid chromatography/time-of-flight/mass spectrometry (LC/TOF/MS) for the analysis of emerging contaminants. TrAC Trends Anal. Chem. 2003, 22, 750-756. [CrossRef]

54. Weber, C.M.; Cauchi, M.; Patel, M.; Bessant, C.; Turner, C.; Britton, L.E.; Willis, C.M. Evaluation of a gas sensor array and pattern recognition for the identification of bladder cancer from urine headspace. Analyst 2011, 136, 359-364. [CrossRef]

55. Khalid, T.; White, P.; De Lacy Costello, B.; Persad, R.; Ewen, R.; Johnson, E.; Probert, C.S.; Ratcliffe, N. A Pilot Study Combining a GC-Sensor Device with a Statistical Model for the Identification of Bladder Cancer from Urine Headspace. PLoS ONE 2013, 8, e69602. [CrossRef]

56. Gao, Q.; Lee, W.-Y. Urinary metabolites for urological cancer detection: A review on the application of volatile organic compounds for cancers. Am. J. Clin. Exp. Urol. 2019, 7, 232-248.

57. Lima, A.R.; Pinto, J.; Carvalho-Maia, C.; Jerónimo, C.; Henrique, R.; Bastos, M.D.; Carvalho, M.; Guedes de Pinho, P. A Panel of Urinary Volatile Biomarkers for Differential Diagnosis of Prostate Cancer from Other Urological Cancers. Cancers 2020, $12,2017$. [CrossRef]

58. Kurata, Y.; Asamoto, M.; Hagiwara, A.; Masui, T.; Fukushima, S. Promoting effects of various agents in rat urinary bladder carcinogenesis initiated by N-butyl-N-(4-hydroxybutyl)nitrosamine. Cancer Lett. 1986, 32, 125-135. [CrossRef]

59. Boyes, W.K.; Bingham, E.; Cohrssen, B.; Powell, C.H. Neurotoxicology and behavior. In Patty's Toxicology; Wiley: Hoboken, NJ, USA, 2001.

60. Heptanal. Available online: https://pubchem.ncbi.nlm.nih.gov/compound/Heptanal (accessed on 16 October 2021).

61. Wishart, D.S.; Tzur, D.; Knox, C.; Eisner, R.; Guo, A.C.; Young, N.; Cheng, D.; Jewell, K.; Arndt, D.; Sawhney, S.; et al. HMDB: The Human Metabolome Database. Nucleic Acids Res. 2007, 35, D521-D526. [CrossRef] [PubMed]

62. National Center for Biotechnology Information. PubChem Compound Summary for CID 15979, Pristane. Available online: https:/ / pubchem.ncbi.nlm.nih.gov / compound/Pristane (accessed on 16 October 2021).

63. Rodrigues, D.; Pinto, J.; Araújo, A.M.; Monteiro-Reis, S.; Jerónimo, C.; Henrique, R.; de Lourdes Bastos, M.; de Pinho, P.G.; Carvalho, M. Volatile metabolomic signature of bladder cancer cell lines based on gas chromatography-mass spectrometry. Metabolomics 2018, 14, 62. [CrossRef] [PubMed]

64. Peng, G.; Hakim, M.; Broza, Y.Y.; Billan, S.; Abdah-Bortnyak, R.; Kuten, A.; Tisch, U.; Haick, H. Detection of lung, breast, colorectal, and prostate cancers from exhaled breath using a single array of nanosensors. Br. J. Cancer 2010, 103, 542-551. [CrossRef]

65. Chung, W.-G.; Yu, I.-J.; Park, C.-S.; Lee, K.-H.; Roh, H.-K.; Cha, Y.-N. Decreased formation of ethoxyacetic acid from ethylene glycol monoethyl ether and reduced atrophy of testes in male rats upon combined administration with toluene and xylene. Toxicol. Lett. 1999, 104, 143-150. [CrossRef]

66. Yu, I.-J.; Lee, J.-Y.; Chung, Y.-H.; Kim, K.-J.; Han, J.-H.; Cha, G.-Y.; Chung, W.-G.; Cha, Y.-N.; Park, J.-D.; Lee, Y.-M.; et al. Co-administration of toluene and xylene antagonized the testicular toxicity but not the hematopoietic toxicity caused by ethylene glycol monoethyl ether in Sprague-Dawley rats. Toxicol. Lett. 1999, 109, 11-20. [CrossRef]

67. Smith, S.; White, P.; Redding, J.; Ratcliffe, N.M.; Probert, C.S.J. Application of Similarity Coefficients to Predict Disease Using Volatile Organic Compounds. IEEE Sens. J. 2010, 10, 92-96. [CrossRef]

68. Jiménez-Pacheco, A.; Salinero-Bachiller, M.; Iribar, M.C.; López-Luque, A.; Miján-Ortiz, J.L.; Peinado, J.M. Furan and p-xylene as candidate biomarkers for prostate cancer. Urol. Oncol. Semin. Orig. Investig. 2018, 36, 243.e221-243.e227. [CrossRef] [PubMed]

69. Wu, H.; Liu, T.; Ma, C.; Xue, R.; Deng, C.; Zeng, H.; Shen, X. GC/MS-based metabolomic approach to validate the role of urinary sarcosine and target biomarkers for human prostate cancer by microwave-assisted derivatization. Anal. Bioanal. Chem. 2011, 401, 635-646. [CrossRef] [PubMed]

70. Lima, A.R.; Pinto, J.; Azevedo, A.I.; Barros-Silva, D.; Jerónimo, C.; Henrique, R.; de Lourdes Bastos, M.; Guedes de Pinho, P.; Carvalho, M. Identification of a biomarker panel for improvement of prostate cancer diagnosis by volatile metabolic profiling of urine. Br. J. Cancer 2019, 121, 857-868. [CrossRef]

71. Phillips, M.; Gleeson, K.; Hughes, J.M.B.; Greenberg, J.; Cataneo, R.N.; Baker, L.; McVay, W.P. Volatile organic compounds in breath as markers of lung cancer: A cross-sectional study. Lancet 1999, 353, 1930-1933. [CrossRef]

72. Cai, X.; Chen, L.; Kang, T.; Tang, Y.; Lim, T.; Xu, M.; Hui, H. A Prediction Model with a Combination of Variables for Diagnosis of Lung Cancer. Med. Sci. Monit. Int. Med J. Exp. Clin. Res. 2017, 23, 5620-5629. [CrossRef]

73. Belugina, R.; Karpushchenko, E.; Sleptsov, A.; Protoshchak, V.; Legin, A.; Kirsanov, D. Developing non-invasive bladder cancer screening methodology through potentiometric multisensor urine analysis. Talanta 2021, 234, 122696. [CrossRef] [PubMed]

74. Kim, Y.-H.; Kim, K.-H. A novel method to quantify the emission and conversion of VOCs in the smoking of electronic cigarettes. Sci. Rep. 2015, 5, 16383. [CrossRef] [PubMed] 
75. Charles, S.M.; Batterman, S.; Jia, C. Composition and emissions of VOCs in main-and side-stream smoke of research cigarettes. Atmos. Environ. 2007, 41, 5371-5384. [CrossRef]

76. McWilliams, A.; Beigi, P.; Srinidhi, A.; Lam, S.; MacAulay, C.E. Sex and Smoking Status Effects on the Early Detection of Early Lung Cancer in High-Risk Smokers Using an Electronic Nose. IEEE Trans. Biomed. Eng. 2015, 62, 2044-2054. [CrossRef] [PubMed] 